\title{
Active Learning Strategies and Competency-Based Design in Research Education: a Longitudinal Review
}

\author{
Noela A. Haughton \\ University of Toledo \\ noela.haughton@utoledo.edu
}

\begin{abstract}
This paper describes the long-term re-development of an introductory graduate research methods course. The initial design is presented, followed by the two re-design phases. Phase 2 introduced additional inquiry-based strategies such as concept mapping and multiple levels of peer collaboration. Phase 3 incorporated competency-based techniques as well as additional technical, social, and instructional support. Assessment results, student feedback, moderate to strong relationships between scores on key assessments, and design principles support the assertion that the Phase 3 course is an improvement over the Phase 1 version. Limitations and further research are presented.
\end{abstract}

Keywords: inquiry-based learning, competency-based design, research methods education, graduate students.

\section{Introduction}

The context of this longitudinal instructional development journey is master's-level research methods and statistics education (RMS), with a focus on preparing students to be informed consumers. This type of preparation in RMS enables students to evaluate research reports accurately and use results for a range of academic and professional purposes (McMillan, 2012; Smith \& Martinez-Moyano, 2012). More typically however, students are prepared to be producers of research, which carries an assumption of being engaged in conducting original research studies (Katzer, Cook, \& Crouch, 1998). The Council of Graduate Schools in the United States reported: master's students accounted for 74\% of enrolled graduate students with master's degrees accounting for $84 \%$ of graduate degrees conferred, mostly in professional disciplines; and, only $6 \%$ of professional programs link research production to the professional success of their graduates (Okahana, Augustine, \& Zhou, 2018). Thus, professional program graduates are more likely to use research-informed best practices to provide services and education to the public, and less likely to be engaged in scholarly research projects (Rodriquez \& Toews, 2005). However, there is an on-going mismatch between this reality, the type of RMS preparation, and the availability of peer-reviewed scholarship addressing RMS consumer preparation.

Extensive searches of the peer-reviewed literature related to master's-level RMS consumer preparation revealed four trends. Firstly, there is a paucity of publications that focuses on best practices in RMS consumer preparation. Trend number two is master's programs continue to struggle with defining the appropriate type of preparation (Brennan, 2011; Cook, 1998; Rodriquez \& Toews, 2005; Shenk et al., 2001; Smith \& Martinez-Moyano, 2012; Tashakkori \& Teddlie, 2003; Wong, 1997), which is also driven by discipline and degree level (Shenk et al., 2001) and accreditation requirements (Brennan, 2011; Cook, 1998; Wong, 1997). The third trend is the continued preparation emphasis on research production, which does not adequately consumer preparation (Barner et al., 1998; Katzer, Cook, \& Crouch, 1998; Wongpinunwatana, Jantadej, \& Jantachoto, 2017). Where they exist, the few publications focused on consumer preparation also included producer emphases (Cook, 1998; Smith \& Martinez-Moyano, 2012; Wong, 1997). This is likely, at least in-part, related to for producerconsumer preparation dilemma (Brennan, 2011), trend number two. Moreover, students in researchfocused producer programs are typically encouraged to choose either a quantitative or qualitative track 
(Tashakkori \& Teddlie, 2003), which further limits preparation. Fourthly and integral to trends one, two, and three, while being an informed RMS consumer is implicitly expected in both professional and research focused programs, this preparation is rarely addressed explicitly in coursework (Katzer, Cook, \& Crouch, 1998; Rodriquez \& Toews, 2005). Thus, consumer preparation results from a "hidden curriculum" (Rodriquez \& Toews, 2005, p. 99), which is not accessed uniformly. Therefore, RMS consumer competences are essential for both professional- and research-focused degree completers, making it imperative to address the preparation gap.

Professional and research focused master's programs, respectively, identified completing requisite course work on time $(79 \%$ and $84 \%)$ and completing the capstone requirement $(75 \%$ and $65 \%$ ) as very important degree completion outcomes (Okahana, Augustine, \& Zhou, 2018). Coursework typically includes required research content and the capstone requirement is oftentimes as a project, paper, or thesis, each of which requires some research preparation. Despite this essential role of their content, and in addition to the foregoing preparation gap discussion, RMS universitylevel teachers, especially in core courses, face additional environmental challenges. Students oftentimes vary in terms of discipline, degree focus, and curriculum completion, all of which lead to variations in prior knowledge and interest. Many students are also apprehensive about their RMS performance prior to beginning coursework (Coleman \& Conrad, 2007; Davis, 2003; Huang, 2018; Rodriguez \& Toews, 2005; Shenk et al., 2001; Smith \& Martinez-Moyano, 2012). The teaching approach to various RMS topics has also been criticized for being abstract and generic (Barr, 2014) and poorly sequenced (Barron \& Apple, 2014). Moreover, depending on degree program and related requirements (Brennan, 2011; Cook, 1998; Okahana, Augustine, \& Zhou, 2018; Shenk et al., 2001; Tashakkori \& Teddlie, 2003), RMS preparation could vary from a single core course to a sequence of courses, further impacting prior knowledge differences. Regardless, university teachers of RMS and similarly challenged courses are still tasked with creating effective learning environments that support each student's learning regardless of the above-mentioned challenges and other enrollment characteristics. Learning environments must be supportive while providing well-sequenced and integrated experiences that allow each student to meet and maintain appropriate performance expectations. Students should also appreciate and value the learning experience beyond the course, especially in terms of post-degree goals (Brennan, 2011; Cook, 1998; Okahana, Augustine, \& Zhou, 2018; Rodriquez \& Toews, 2005; Shenk et al., 2001; Smith \& Martinez-Moyano, 2012; Tashakkori \& Teddlie, 2003; Wong, 1997). For RMS courses, this also includes overcoming pre-course anxiety and other negative feelings (Coleman \& Conrad, 2007; Cook, 1998; Davis, 2003; Huang, 2018; Rodriguez \& Toews, 2005; Shenk et al., 2001; Smith \& Martinez-Moyano, 2012).

This paper describes one university teacher's 8-year continuous improvement journey to address the forgoing challenges by redeveloping an RMS core course. The two overarching goals of the redesign were to close the consumer preparation gap the RMS curriculum and to describe students' responses towards the updated course in terms of design elements, relevance, and satisfaction. This redevelopment is presented in three distinct phases. Phase one is the original course design. Phase two documents the integration of inquiry-based components including concept mapping and collaborative and peer assessment strategies. Phase three documents the incorporation of a competency-based approach that further aligned course experiences with real-world performance expectations (McClelland, 1973), which in turn, support positive and far transfer (Schunk, 2012). Though the context of the redevelopment journey is RMS education, both update phases at their core, were focused on student learning and instructional effectiveness. Thus, the journey itself, which describes the implementation of theoretically-supported instructional strategies, is pertinent to instructional development in any disciplinary context, especially core courses with the similar challenges. This makes this work significant for a broad spectrum of readers engaged in understanding and improving university-level teaching and instructional design. 


\section{Methods and Procedures}

\section{Setting}

The research setting is a Foundations of Education (FOE) department within a college of education at a mid-sized, Midwestern university. FOE houses multiple programs including RMS. The RMS program has a dual function within the institution. Firstly, it is home to a graduate program and secondly it provides undergraduate and graduate service courses to multiple colleges and programs across the university.

\section{The Students}

This course typically enrolled 15 to 32 students from several colleges during the 2008 to 2016 timeframe of this study. It was also the only research course for some while for others, it was part of a sequence of research methods coursework. Students in the current sample were drawn from several offerings across 8 academic years and represented multiple disciplines including Education, Health Science, Human Service, Nursing, and Business. They also varied in terms of number of semesters completed, research prior knowledge, and degree level with the majority enrolled in master's programs.

\section{The Initial Course: Phase 1(2008-2010)}

The focus course, RMS 600, is a three-credit, graduate-level core course with an overarching goal of preparing students to be effective consumers of research in their respective disciplines. It has five modules: Foundations of Research, Basic Measurement and Statistical Concepts, Quantitative Designs, Qualitative Designs, and Mixed Methods Designs and Action Research. It was offered every semester with the following learning objectives (SLOs):

1. develop a "skeptical and critical eye" for educational research studies

2. understand the process of conceptualizing and conducting research

3. understand the appropriate use of research methodologies

4. understand the strengths \& weaknesses of research methodologies

5. evaluate, critique, and use published studies and reports

6. understand the process of conducting action research.

The course was taught face-to-face only during this phase. Each module had assigned materials including journal articles that students were expected to prepare and read ahead of class meetings. The first half of each meeting was primarily lecture-based while the second half was dedicated to contentrelated class activities including collaborative research evaluation of assigned articles and student presentations. The course's assessment system aligned with Bloom's cognitive taxonomy (Bloom, Engelhart, Furst, Hill, \& Krathwohl, 1956) and each assessment is described including the SLO alignment.

- Individual Content Knowledge: Chapter Practice Tests 30\%. Content knowledge was assessed by several single-attempt chapter tests, each with 15 to 20 questions. These tests were administered via the textbook's assessment site. This Knowledge level assessment supported all SLOs. 
- Individual Participation 10\%. Participation was assessed based on class attendance and evidence of preparation based on strength of participation in-class activities and presentations. This primarily Application level assessment supported all SLOs.

- Group Participation: Research Assessment Tool (RAT) 20\%. Students worked in groups to develop RATs that were then used to evaluate research articles. The RAT is a check-list of scoring criteria that reflect RMS best practices that are supported by textbook citations. This assessment was developed and added in 2008 when it was first taught by the author. The RAT development and application satisfied the need to objectively determine how well students were understanding and applying RMS concepts to research evaluation. It was intended to and continues to serve as a method of making students' thinking visible in terms of content meaning, application, and decision making. As shown in Figure 1, a minimum of two to three questions per research criterion were clustered within broader research components (e.g., Title, Abstract, Research Problem, Literature Review, etc.). Scores had to be supported with evidence from the article. Four RATs are developed throughout the course. The first RAT is a foundational RAT for simple reports and includes all major research report sections from title and abstract to conclusion.

The remaining three RATs are for quantitative, qualitative, and mixed-methods designs, respectively. Each of these RATs is derived from the foundational RAT and includes modifications based on the respective content from Modules 3, 4, and 5. This assessment focused primarily on the Analysis, Synthesis, and Evaluation levels and aligned directly with SLOs 1, 5, and 6. RAT development and application simulate the research evaluation process and scaffold final project requirements.

- Group Participation: Peer Assessment 10\%. Each group was required to peer review other RAT development and application throughout the course. Eligibility also depended on class attendance. This assessment aligned with SLOs1, 5, and 6.

- Group: Final Project Research Assessment 30\%. This culminating assessment required each group to independently select a published peer-reviewed journal article, conduct an evaluation using the appropriate RAT, deliver a presentation, and submit a final report. The final report includes a discussion of search and selection criteria and a summary of the article. This assessment aligned primarily with SLOs 1, 3, 4, 5, and 6 . 


\begin{tabular}{|c|c|c|c|c|}
\hline \multicolumn{5}{|c|}{ Complete Foundational RAT in Modules 1 and 2. Revise and Refine in Modules 3, 4, and 5} \\
\hline Research Criteria from Readings & & & 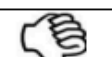 & Evidence from Research Report \\
\hline \multicolumn{5}{|l|}{ Title: How descriptive is the title } \\
\hline \multicolumn{5}{|l|}{$\begin{array}{l}\text { describes purpose of study } \\
\text { (Sylvester \& Tweety, 2012, p.1) }\end{array}$} \\
\hline \multicolumn{5}{|l|}{$\begin{array}{l}\text { reflects variables (quant) or central } \\
\text { phenomenon (qual) being studied } \\
\text { (Sylvester \& Tweety, 2012, p.1) }\end{array}$} \\
\hline $\begin{array}{l}\text { reflects who is being studied } \\
\text { (Sylvester \& Tweety, 2018, p.1) }\end{array}$ & & & & $\begin{array}{l}\text { The title clearly references first } \\
\text { generation college students from } \\
\text { immigrant families. }\end{array}$ \\
\hline \multicolumn{5}{|l|}{ Research Problem } \\
\hline $\begin{array}{l}\text { clearly stated } \\
\text { (Sylvester \& Tweety, 2012, p.5) }\end{array}$ & & & & $\begin{array}{l}\text { Though not clearly stated, the } \\
\text { authors discuss issues related to } \\
\text { college access for first generation } \\
\text { students from immigrant families } \\
\text { on page } 12 .\end{array}$ \\
\hline \multicolumn{5}{|l|}{$\begin{array}{l}\text { describes theoretical significance } \\
\text { (Sylvester \& Tweety, 2012, p.5) }\end{array}$} \\
\hline $\begin{array}{l}\text { describes practical significance } \\
\text { (Sylvester \& Tweety, 2018, p.5) }\end{array}$ & & & & $\begin{array}{l}\text { The authors discuss how higher } \\
\text { education institutions can help to } \\
\text { remove barriers to support first } \\
\text { generation college students from } \\
\text { immigrant families on page } 13 \text {. }\end{array}$ \\
\hline
\end{tabular}

Figure 1. A Sample of Research Assessment Tool (RAT) Components

\section{Data Sources}

Student pass rates and course evaluation data - quantitative and qualitative - were examined. The FOE's course evaluation administration procedures remained fairly stable between 2008 and 2016 with only minor adjustments to the questionnaire. Each questionnaire was administered the last week of the course and had 20 items including three open-ended questions about course and materials, the professor, and general issues. The close-ended questions are worded positively such as "the course objectives were clear"; the four-point Likert-type scale choices were: strongly disagree, disagree, agree, and strongly agree. For the purpose of this analysis, the four options were collapsed into two and the results were presented as percentages who agreed with each statement. The following six design and satisfaction statements were included across the 8-year period: 1. value of assignments, 2. clarity of course objectives, 3. weights of assignments, 4. grading criteria, 5. whether the course increase knowledge, and 6. whether the course would be recommended. Statements 1 through 4 were used to gauge design decisions such as sequencing and the concreteness of the content (Barr, 2014; Barron \& Apple, 2014), statements 1 and 5 gauged relevance, and statement gauged overall satisfaction (Shenk et al., 2001; Davis, 2003; Rodriguez \& Toews, 2005). Qualitative comments were also used to inform design decisions, gauge relevance and satisfaction, and provide a window into possible anxiety and other negative feelings (Coleman \& Conrad, 2007; Davis, 2003; Huang, 2018). 


\section{Results: Phase 1 (2008-2010)}

\section{Assessment Outcomes}

Figure 2 describes both the summary assessment results across the three phases and concept map scores (introduced in Phases 2 and 3). The average content knowledge, participation, and final project scores in Phase 1 were $89.75 \%, 92.13 \%$, and $79.50 \%$ respectively.

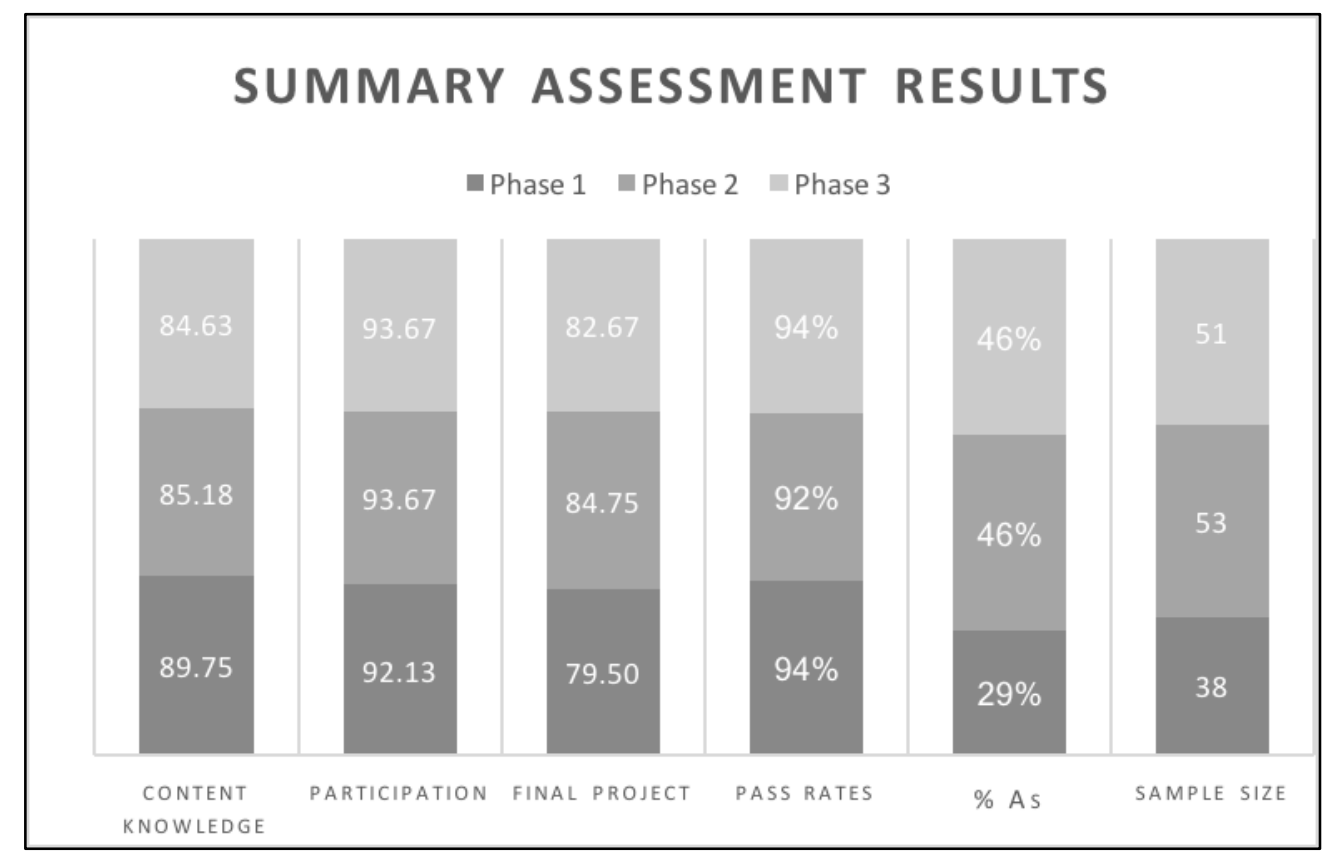

Figure 2. Assessment Results for Phase 1, Phase 2, and Phase 3.

Ninety four percent of the students were successful with 29\% earning $95 \%$ or higher across all assignments (A grade). Students did extremely well on the chapter tests and creating the RATs. Groups chose good quality articles, used the correct RATs for their chosen articles, and used the RAT to score most report sections accurately. The inaccurately scored sections were primarily in quantitative research methods followed by qualitative methods. The evidence from the participation and group activities showed some students not contributing adequately. This pattern continued with the final project presentations and reports where they struggled to summarize and discuss their respective articles' contents beyond the RAT scores.

\section{End-of-Course Student Feedback}

The Phase 1 quantitative feedback was generally positive in terms of design elements. Students thought the assignments were valuable (97\%), the objectives were clear $(84 \%)$, the assignments were fairly weighted $(90 \%)$, and the grading criteria were clear $(85 \%)$. In addition to valuable assignments, students also thought the course increased their knowledge (90\%). They were also mostly satisfied with $(77 \%)$ saying they would recommend the course. Most students did not provide qualitative feedback. The available comments were mixed and some were struggling with the course materials and workload. Some thought the book was "wordy", "contradictory", and "very unhelpful". Others expressed a need additional support such as in the form of "powerpoints" and "more of an outline approach". One thought the materials were good but the book was too expensive and others began 
to "more fully understand the materials at the end of the semester". Some students wanted more time to work on group projects while others wanted less activities and assignments, more points for the assignments, and extra credit opportunities.

\section{Reflections on Results and Subsequent Improvements}

While the assessment and feedback data were mostly positive, a closer inspection of some design elements beginning with the SLOs and the assignments revealed the need for re-design, related to closing the consumer preparation gap (Brennan, 2011; Cook, 1998; Rodriquez \& Toews, 2005; Smith \& Martinez-Moyano, 2012; Tashakkori \& Teddlie, 2003; Wong, 1997). The development of a "skeptical and critical eye" (SLO1) was the course's overarching consumer purpose and should be confirmed by assessments results, making this SLO redundant. SLOs 2, 3 and 4 were likely written to address both consumer and producer goals. SLO5 was the culminating objective and reflected what an informed consumer should be able to do. SLO 6 (understanding the process of conducting research) was very similar to SLO 2, and thus redundant. The second design issue addressed was the realignment of activities and assessments with consumer preparation. The RAT development and application activities aligned well with SLO5. However, individualized assessments beyond the Knowledge and Comprehension levels were either lacking and/or did not align well enough with a consumer purpose. This assertion was supported by available student feedback such as "the assignments should allow students to better understand and apply the concepts", "spread out the discussion chapters more", and, "the day we all looked up questions and discussed them was the most beneficial". Inadequate individual accountability allowed some weaker and low-participating students to benefit too much from their stronger peers as shown by the average participation score. A fourth and related design issue was the need to re-distribute points away from the lower-level cognitive chapter tests to higher order assessments. The subsequent updates used inquiry-based strategies to improve the alignment with consumer preparation, while addressing individual accountability.

Inquiry-based learning is a multifaceted concept that is associated with a range of strategies including project-based learning, student-centeredness, collaboration, flexible thinking, scaffolding, lifelong learning, and communication (Avsec \& Kocijanic, 2016; Hannafin \& Land, 2000; Hannafin, Land, \& Oliver, 1999; Kim \& Hannafin, 2011; Jonassen, 2000; Mayer \& Wittrock, 2006; SaundersSteward, Gyles, \& Shore, B., 2012; and Scardamalia \& Bereiter, 2010). These can strategies help to mitigate college teaching's overreliance on lower-level learning goals, lecture, and discussion (Fink, 2003). Implementing inquiry-based approaches involves a deliberate design for knowledge creation as well as social and technological support that promotes "epistemic agency" (p. 5) among students (Scardamalia \& Bereiter, 2014). Activities such as inventing, theorizing and constantly searching transfer knowledge creation responsibilities from the teacher to the student (Scardamalia \& Bereiter, 2014). Inquiry-based strategies align with moving beyond lower level assessments to favor higherorder outcomes that reflect knowledge creation and real-world performance expectations.

\section{Phase 2 (2011-2013): Re-design for Inquiry-Based Learning}

\section{Changes to Design Elements: Goal, Learning Objectives, and Assessment System}

Phase 2 began with updating the course description and SLOs to improve alignment with RMS consumer preparation and to support online course delivery. The description changed to include the ability to critically assess the quality of research reports by examining each component and making an overall judgment on the quality of the report based on defensible criteria. SLOs were restructured as follows:

Journal of the Scholarship of Teaching and Learning, Vol. 19, No. 4, October 2019. josotl.indiana.edu 
SLO1: Describe, differentiate, and inter-relate major activities involved with conceptualizing and conducting research. This reflected understanding the research process from developing a title to stating conclusions and how each supports the others.

SLO2: Describe, differentiate, and inter-relate the major components of a research study. This reflected understanding of the major parts of a research report and how they related to each other and the overall report.

SLO3: Describe and differentiate between the major types of research methods and approaches. This reflected understanding of research methods sub-sections for the respective approaches.

SLO4: Develop the skills to evaluate quantitative, qualitative, and mixed methods research. This reflected developing and using the RATs for each type of research report throughout the course. SLO5: Demonstrate the ability to evaluate quantitative, qualitative, and mixed methods research. This reflected the culminating experience of using RATs to evaluate independently chosen published articles, a real-world simulation of an informed research consumer.

The SLOs had an explicit hierarchy with SLOs1, 2, 3 at the lower to mid taxonomy levels and foundational to SLO4, which in turn, was foundational to SLO5. SLOs 4 and 5 assessed at the highest taxonomy levels.

Rebalancing the assessment system in terms of the number assignments, point distribution, and individual accountability followed:

Group Participation 15\%. This included RAT development, peer review, and general online and in-class participation. This remained a group assignment because of the value of the social knowledge construction process.

Individual Homework $60 \%$. This was a series of four homework concept maps that replaced the chapter tests.

Final Project 25\%. This was mostly unchanged but had a lower point value and the option to work independently.

Group and individual assignments were changed to $40 \%$ and $60 \%$ of the course grade respectively.

\section{Changes to Learning Experiences and Assessments}

\section{Concept Mapping}

The replacement of chapter tests with homework assignments was a major change to the learning experiences and assessment system. Homework comprised of four concept maps for Module 1 (Foundations), Modules 2 and 3 (Basic Measurement and Statistics and Quantitative Designs), Module 4 (Qualitative Designs), and Module 5 (Mixed Methods and Action Research) respectively. Each homework assignment had 20 to 30 core concepts, the understanding of which, supported the current course's learning goals as well as research coursework beyond this course (Barner et al., 1998; Katzer, Cook, \& Crouch, 1998; Okahana, Augustine, \& Zhou, 2018; McMillan, 2012; Rodriquez \& Toews, 2005; Smith \& Martinez-Moyano, 2012). Assessment was criterion-based as follows: inclusion of all required concepts; correct definition of each concept; credible citations for each concept; all concepts linked; and, accurate descriptions of relationships between linked concepts. Concept mapping as a mind-tool supports critical thinking and knowledge development (Jonassen, 1996). Concept mapping is used to depict structural knowledge and to visually describe the relationships between concepts and ideas in the domain of interest (Jonassen \& Grabowski, 1993). Examples of completed practice 
concept maps are shown in Figure 3. Each map represented the following concepts: clothing, pants, shirt, hat, shoes, and socks. Each student's presentation, though different, accurately portrayed the relationships between concepts. This is the case for any assignment requiring structural knowledge depiction (Jonassen \& Grabowski, 1993).

Concept map assignments provided many instructional benefits. It extended the cognitive level of content knowledge assessments to include application, analysis, and synthesis. Annotated comments by the instructor on each map provided targeted and individualized feedback that was summarized to address class-level misconceptions.

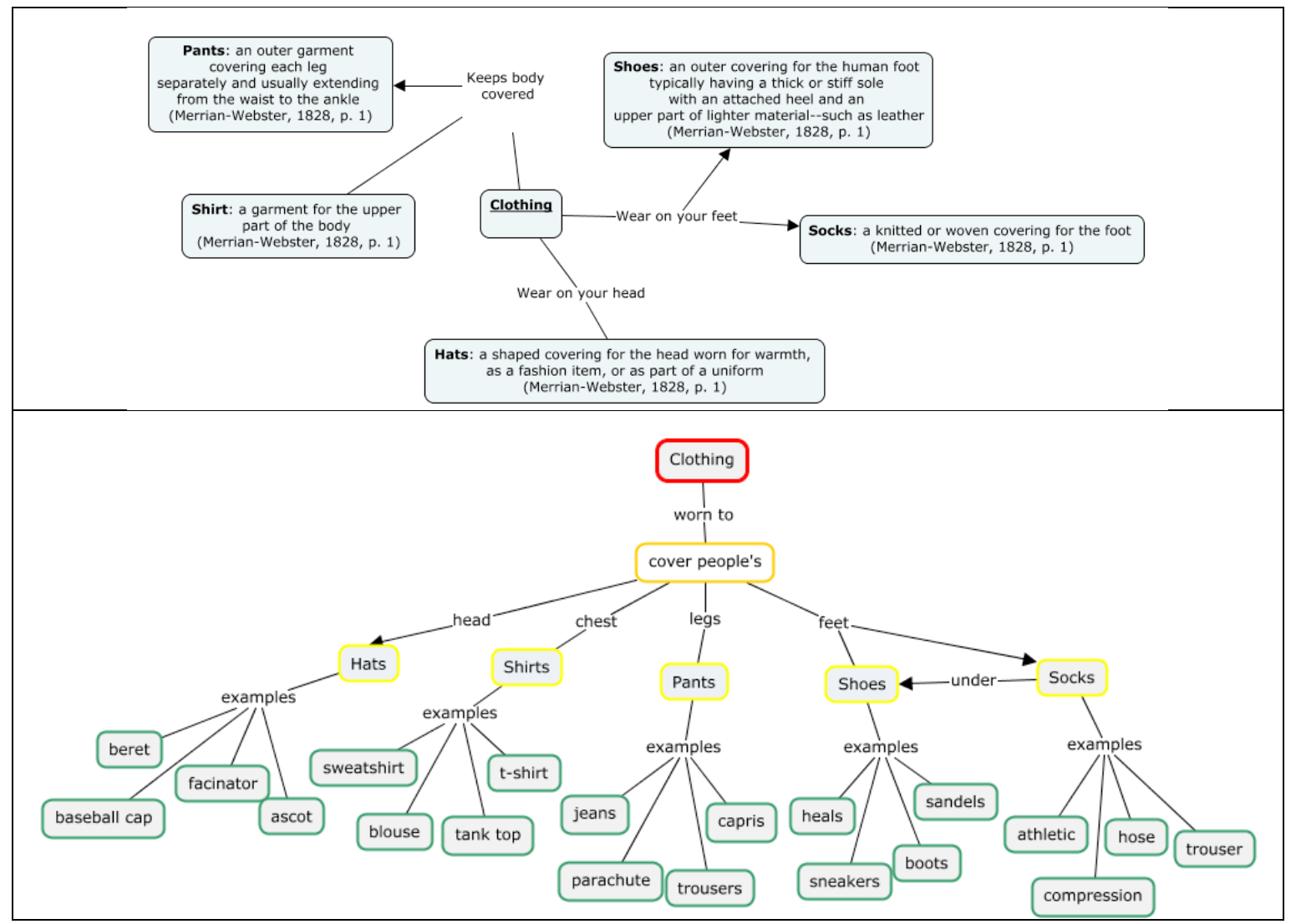

Figure 3. Two sample practice concept maps submitted during Orientation week

Each map was an individualized and flexible method to assess each student's research knowledgebase. Multiple knowledgebase representations supported integration of prior knowledge, which varied among students. Concept mapping also enabled students to extend their understanding by adding additional research concepts, thus going beyond minimum assignment expectations.

\section{Collaboration}

Changes were made to the participation requirements to improve the integration of project components, research evaluation skills, and individual accountability. A two-layer web-supported structure was implemented in the learning management system (LMS). Layer one - within-group collaboration - allowed students to work in teams of three or four for the duration of the course. Each group's use of the LMS to develop their RATs and evaluate practice articles made individual participation more visible. Layer two - between group collaboration -allowed for cross-group peer 
review of RATs and article evaluations. The two-level collaboration strategy supported a social constructivist environment that aligned with zone of proximal development principles (Vygotsy, 1978). It also provided additional social and technological support (Scardamalia \& Bereiter, 2014) and responds to student feedback.

Minimal changes were made to the final project to support online course delivery. Each group or individual was still required to deliver a presentation in the form of an annotated (voice-over) PowerPoint or similar software program. Group submissions required the presence of each member. Online presentations were posted for peer review, enabling students to share ideas and research across disciplinary domains.

\section{Assessment Results}

Referring to Figure 2, Phase 2 pass rate was 92\%, slightly slower than Phase 1's. Students on average earned $85.18 \%, 93.67 \%$, and $84.75 \%$ on the content knowledge, participation, and final project components of the course respectively. A larger share of students, $46 \%$, earned A grades. Average scores on the concept maps were 87\%, 81.50\%, 82.25\%, and 90\% for Foundations, Quantitative, Qualitative, and Mixed Methods Action Research, respectively. The highest performing students in the course excelled on the homework assignments, took the lead in the group assignments, and submitted high-quality final projects. These students tended to be extremely invested and refused to allow others to negatively impact their grade, with some vocally objecting to "group work".

Comparing Phase 1 and 2 outcomes, the average content knowledge score dipped while participation and final project scores improved. The content knowledge score, while lower, resulted from more rigorous assignments that were aligned with consumer preparation and were better representations of achievement. The LMS records documented and tracked the continued struggle of some students with participation, which supported more accurate grading. Performance on the final projects though still mixed, improved in some areas including summarizing evaluation results, which is critical to the consumer purpose. Also, individualized project submissions further enhanced student accountability by unmasking performance issues that were previously hidden in the group submissions, making the current scores more accurate reflections of learning. General areas of strength continued to be choosing good quality articles and accurate RAT scoring especially in the introductory sections. Weaker students also continued to struggle with discussing the meaning of the article sections in summary terms beyond the actual scores on their RATs. The most inaccurate scoring and weakest evaluations were in the methods sections with students on average earning $77 \%$ of the eligible points. The struggle with the research methods and design content extended to the concept maps as shown by the lower average scores.

\section{End-of-Course Student Feedback}

The quantitative feedback continued to be mostly positive but with some changes from. Comparing Phase 1 with Phase 2, students still thought the assignments were valuable (97\% vs. 94\%), the objectives were clear ( $84 \%$ vs. $88 \%$ ), the assignment were fairly weighted $(90 \%$ vs. $83 \%)$, and the grading criteria were clear ( $84 \%$ vs. $75 \%$ ). Though most thought the course was relevant (valuable assignments and increased knowledge), less students thought the course increased their knowledge (90\% vs. $81 \%$ ) and would recommend the course (77\% vs. 65\%). As with Phase 1, most students did not provide qualitative feedback and online students participated even less. Once again, the available feedback was contradictory and likely depended on extremes - very high performers vs. those who struggled most. "Notes are amazing! Don't know how some students can't figure it out"; "really disliked how the course was set up"; "participation is not entirely necessary to do well in this class";

Journal of the Scholarship of Teaching and Learning, Vol. 19, No. 4, October 2019.

josotl.indiana.edu 
and, "maybe make future online participation optional?" Some thought "the course \& support were organized" and the "materials were relatively easy until it ran to the exams".

\section{Reflection on Results}

The use of active learning strategies led to several positive Phase 2 outcomes. It supported the redesign with a range of project-based, student-centered, and collaborative design elements (Avsec \& Kocijanic, 2016; Hannafin \& Land, 2000; Kim \& Hannafin, 2011; Jonassen, 2000; Mayer \& Wittrock, 2006; Saunders-Steward, Gyles, \& Shore, B., 2012; and Scardamalia \& Bereiter, 2010). It provided a basis for linking grade points to higher cognitive levels and improving individual accountability. It facilitated the conversion of the initial course to a completely consumer focused, thus removing this type of RMS education from the hidden curriculum (Rodriquez \& Toews, 2005). The integration of concept mapping homework assignments allowed students to engage at higher and deeper cognitive level (Jonassen \& Grabowski, 1993) and introduced a skill that can support their learning in other contexts beyond the current course (Okahana, Augustine, \& Zhou, 2018; Scardamalia \& Bereiter, 2014; Fink, 2003). These homework assignments also provided better performance-based evidence of understanding RMS content at both the individual and class levels, and therefore, provided a stronger foundation for RMS consumer skills. An analysis of scores from the four homework assignments confirmed students struggled most with quantitative methods. It further confirmed an anecdotal trend of students believing qualitative research is easier than quantitative. Students tended to be more relaxed upon completion of the quantitative modules, had higher average scores on qualitative design assignments, and tended to choose qualitative research articles for their final projects.

Even though the Phase 2 course was successful on several dimensions, the objective and subjective evidence also indicated the need for additional design updates and instructional support. A clearer connection between design elements namely course assignments would also be beneficial for both the instructor and students, from the perspectives of instructional delivery and understanding, respectively. Design strategies such as Significant learning Experiences (Fink, 2003) and Backwards Design (Wiggins \& McTighe, 2005) support real-world connections, which in turn, support understanding and performance. While elements of these strategies were implemented in Phase 2, additional work in terms of contextualizing and presenting course elements was needed. Competencybased approaches support contextualizing within real-world settings, and therefore, clearer performance expectations.

\section{Phase 3 (2014-2016): Re-design for Competency-Based Approach}

Several learning frameworks discuss the concept of competency. The Conceptual Learning Model (U.S. Department of Education, 2002; Voorhees, 2001) presents competences as a series of integrative building blocks leading to real-world performance and growth in mastery. Competences can crossfunctional such as being able to communicate and collaborate effectively (Rothwell \& Graber, 2011). The Bologna Process along with the Dublin Descriptors (CoRE Project Team, 2010; ESG, 2015) and the Degree Qualifications Profiles (DQP) (Lumina, 2014) integrate the notions of competency and mastery to describe learning outcomes associated with higher education degrees across disciplinary boundaries. The Author's Ready Develop Integrate Perform (RDIP) Model, as shown in Figure 4, is a derivation of the above-mentioned frameworks. The model is used to inform the design, integration, sequencing, and communication of elements within the learning experience at both the curriculum and course levels (Author, 2017, 2018a, 2018b). Figure 4 is a partial presentation of the model and focuses on course-level design.

Journal of the Scholarship of Teaching and Learning, Vol. 19, No. 4, October 2019. josotl.indiana.edu 


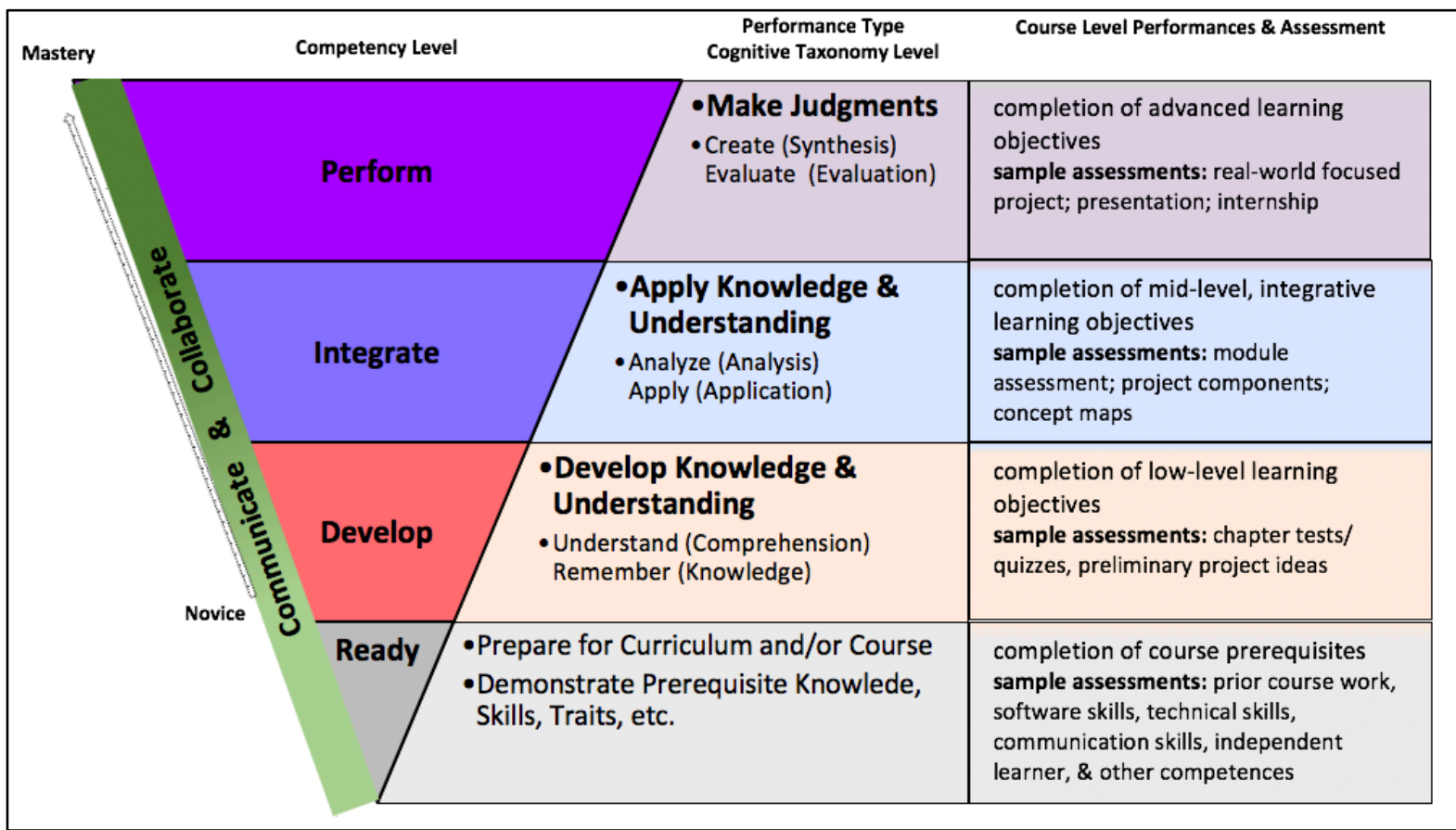

Figure 4. Author's Ready Develop Integrate Model (partial model shown)

The inverted pyramid and arrow leading from novice to mastery are metaphors for growth in learning and competency including communication and collaboration, which are essential academic and professional skills (CoRE Project Team, 2010; ESG, 2015; Lumina, 2014). Having satisfied foundational entry requirements (Ready), learners progress from novice (Develop) to mastery (Perform). The types of performances and related assessments are described at each progression. The adjoining table relates learning experiences, types of performance, and assessment through the lens of the widely applied Bloom's Cognitive Taxonomy (1952). Learners must develop the ability to communicate in a variety ways and contexts, to a variety of stakeholders and must also be able to engage in successful collaborative work (CoRE Project Team, 2010; ESG, 2015; Lumina, 2014). The RDIP model was applied to further relate and sequence RMS 600's design elements as well as frame these elements within the broader higher education degree context.

The RMS 600 core course has no research content prerequisites. However, the idea of readiness should not be limited to prior content knowledge. A Ready disposition may require technical competences (Rothwell \& Graber, 2011) such as software skills. For master-level students, readiness extends to building on undergraduate-level competences including independent learning and critical thinking (CoRE Project Team, 2010; ESG, 2015; Lumina, 2014). Develop is the foundational competency level of the learning experience that focuses on knowledge acquisition, development and understanding, and preliminary application and analysis. Each module in RMS 600 presents new research content and students continuously expand and their RMS consumer knowledge base. Learning is supported by "knowledge checks" in the form of in-class activities and quizzes that are mostly at the lower taxonomy level. These and other activities such a scaffolded RAT implementation and preliminary project discussions prepare learners for the next competency progression and midtaxonomy-level assessments. Integrate is the mid-level competency that is focuses cross-disciplinary application of RMS knowledge and understanding. Scaffolded activities simulate real-world performances, thus providing a bridge between new knowledge and real-world applications. Learning is supported by in-class activities that are primarily at the application and analysis taxonomy levels. Students apply RATs to analyze and summarize report sections (e.g., research significance, literature 
review, sampling, etc.), begin to consider the reports holistically, and complete practice peer reviews. Module assignments such as the concept mapping homework synthesis assignments and the module article evaluation transition students to highest taxonomy levels and prepare students for the next progression and the culminating assessment. Perform is the highest competency level and learners should be engaged in applied activities that requires making judgments and working independently in real-world performance settings (CoRE Project Team, 2010; ESG, 2015; Lumina, 2014). Choosing and evaluating the quality of research using best practices reflect the real-world performance of RMS consumers in any discipline. The final project requires students choose a published peer-reviewed article from their respective areas of interest, conduct, present, and write an evaluation of the article using sound research criteria reflected in their RATs. Communication and Collaboration skills are developed throughout the course as students engage in class activities, module peer reviews, and final presentations. These opportunities support the development and use of RMS language as academic as part of consumer preparation.

The RDIP model provided an integrative yet practical lens to examine, simplify, and present course elements as unified system that is connect to practical real-world RMS consumer activities. This in turn, facilitated the review of the Phase 2 course redesign with fresh eyes and helped to identify design and learning experience gaps. Addressing these gaps led to several updated design elements that created the Phase 3 course.

\section{Changes to Design Elements: Learning Objectives and Competency Statements}

Competency level statement aligning the SLOs to the RDIP progression levels were added. This enabled the identification of Phase 2 SLO gaps such as misalignment with RMS content progression, and taxonomy and competency levels. The SLOs were further refined to reflect RDIP competency progression.

1. Define key qualitative and quantitative research paradigms and methodologies Having Knowledge and Understanding

This updated SLO addressed the philosophical and epistemological foundations of the major research approaches - quantitative and qualitative. This is foundational to understanding how both approaches complement each other and improved the alignment with the Develop competency level and concept map assignments.

2. Explain relationships between key research paradigms and methodologies Applying Knowledge and Understanding

This update added clarification to each module's content, improved the alignment with the Integrate competency level and the concept map assignments, and provided a foundation for RAT development.

3. Differentiate between the major components of research reports Applying Knowledge and Understanding

This update further clarified each module's content. It also improved the alignment with the Integrate competency level and the concept map assignments, and provided a foundation for RAT development. 
4. Develop evaluation strategies for quantitative, qualitative, and mixed methods research reports based on best practices Applying Knowledge and Understanding; Making Judgments

This update bridged knowledge and understanding to the judgment-based actions needed for effective and accurate research evaluation and linked new content to the evaluation process.

5. Critique quantitative, qualitative, and mixed methods research reports using developed evaluation strategy Making Judgments

This updated SLO is a better reflection of the culminating competence and improves the alignment with SLOs 1-4.

Additionally, the following statements were added to the syllabus:

All SLOs address Communication and Collaboration competences. All students are expected to communicate their knowledge and ideas effectively in writing, orally, and with the support of Information and Communications Technologies (ICTs) as required.

Communication and Collaboration expectations at the master's level (CoRE Project Team, 2010; ESG, 2025; Lumina, 2014) transcend the classroom and bring these learning expectations to a broader context (Okahana, Augustine, \& Zhou, 2018).

The RDIP model framed the Phase 3 modifications and the development of RMS consumer competency from novice to mastery (U.S. Department of Education, 2002; Voorhees, 2001). This framing also enabled the instructor to get a clearer sense of how assessments are working as a collective whole, as well as, how performances aligned with larger curricular goals and professional expectations. The competency language provided a script to discuss these important theory-to-practice ideas with students.

\section{Changes to Learning Experiences and Assessments}

Design updates to both the content and the assessment system were informed by the RDIP model, and Phases 1 and 2 student performance and feedback data. Additional RMS foundational content was added to support the new SLO1. Chapter tests were reintroduced as optional extra credit and to serve as knowledge checks. These assessments also directly addressed SLO1 and the Develop competency level. The four chapters test (quizzes) together were worth 5 points. Those in Modules 2 and 3 had more concepts and were worth more, 1.5 points each. As a design element, students were allowed unlimited attempts until the last day of the course and the highest scores counted towards the final grade. This foundational knowledge building strategy extended the students' interaction with the course materials through extended practice, coding, and rehearsal, and support self-regulated learning (Pintrich \& De Groot, 2009; Schunk, 2012). Beyond being motivated by extra credit, the additional 5 points had the pragmatic purpose of allowing students some limited ability to make up for poor performance in the earlier part of the course.

Level of technological, social, and instructional support were enhanced with additional LMS design updates. Two non-graded discussion forums were added. Course Questions (monitored by the instructor) provided space for clarification and feedback to all students, which functioned like a dynamic frequently asked questions (FAQs) list. Student Lounge enabled additional, non-graded discourse between students outside of peer review. All assignment documents along with grading 
criteria and rubrics were placed in a second and more visible location called Grading Criteria. An orientation module was added that included a practice concept map (Figure 3) and an introductory blog. Orientation addressed the Ready level of the RDIP model in a number of ways. The practice map supported the development of key core and technical prerequisite concept mapping and LMS competences prior to a high-stakes assessment. The blog fostered social presence and communication especially for online learners. Finally, and in support of the Develop-level competency, an electronic statistics tutorial with embedded activities, was added and integrated throughout Modules 2 and 3. While RMS 600 not a "statistics course" per se, knowledge if basic statistics supports the research evaluation process, especially for quantitative research. Thus, the tutorial provided content support for previously identified areas of weakness: basic statistics, measurement, and research design principles. The implementation of the tutorial and extra credit quizzes together should help to reduce pre-course RMS anxiety (Coleman \& Conrad, 2007; Cook, 1998; Davis, 2003; Huang, 2018; Rodriguez \& Toews, 2005; Shenk et al., 2001; Smith \& Martinez-Moyano, 2012).

\section{Assessment Results}

Referring to Figure 2, Phase 3 pass rate was 94\%, reflecting a slight increase over Phase 2's 92\%. Students on average earned $84.63 \%, 93.67 \%$, and $82.67 \%$ on the content knowledge, participation, and final project components of the course grade respectively. A grade-earners remained at $46 \%$. Average scores on the concept maps were $87 \%, 81.50 \%, 82.25 \%$, and $90 \%$ for Foundations, Quantitative, Qualitative, and Mixed Methods Action Research respectively. Estimated Develop, Integrate, and Perform performance levels were, on average, 93.67\% (based on the participation score), $85.20 \%$ (the average concept map scores), and $82.67 \%$ (average the final project score).

Comparing Phase 2 and 3 outcomes, the average scores on Research Foundations and Mixed Methods and Action Research were lower while average scores on Basic Measurement and Statistics, Quantitative Designs and Qualitative Designs were higher. The performance patterns continued with the highest performers excelling on all concept map assignments, taking the lead in the collaborative assignments, and avoiding "group work" by opting to submit individual final projects. Interestingly, these students also made the most of the extra credit opportunities by earning all 5 quiz points. Most of the weaker students did not attempt all extra credit quizzes and/or did not earn all available points. They also contributed less to collaborative activities and also wanted to work in teams on the final project. Performance on the final project continued to be mixed with much of the struggle still occurring in the research methods section, with students on average, earning $75 \%$ of the eligible points, slightly lower than Phase 2.

\section{End-of-Course Student Feedback}

The Phase 3 quantitative feedback continued to be mostly positive but with some changes. Comparing the Phase 2 and Phase 3 design elements, less students thought the assignments were valuable (94\% vs. $83 \%$ ), the objectives were clear $(88 \%$ vs. $66 \%)$, and the assignments were fairly weighted $(83 \%$ vs. $66 \%)$; more thought the grading criteria were clear (75\% vs. $83 \%$ ). In terms of relevance and in addition to the assignments being valuable, more students thought the course increased their knowledge (81\% vs. $83 \%$ ). Finally, in terms of satisfaction, more would recommend the course $(65 \%$ vs. $83 \%$ ). While most students followed the trend of not providing qualitative feedback, the available comments were definitely more positive. Feedback on design elements - materials, assignments, structure, delivery - included: "enjoyed the modules"; "good organization"; "materials were good"; "provides both text books and other things on blackboard"; "recommend free resources before purchase if text"; "she also made the course perform both at a distance learning and a face to face

Journal of the Scholarship of Teaching and Learning, Vol. 19, No. 4, October 2019.

josotl.indiana.edu 
course. I appreciated performing both"; "I enjoyed the home work formatting provided"; and, "discussions worthwhile". Beyond the worthwhile discussions, qualitative feedback also indicated progress related the relevance and teaching of RMS topics: "great job at making abstract research course topic relatable". The news regarding workload was still mixed with one student saying "too much reading".

Taken together and notwithstanding some conflicting quantitative vs. qualitative feedback, the objective and subjective evidence indicate that many Phase 3 design and instructional goals were met. This conclusion was further supported by the following results of correlational analyses of the Phase 3 assessment scores:

- Quizzes: Quiz 2 Basic Statistics and Quantitative Designs with Quiz 3 Qualitative Designs ( $r$ $=.851, p<.001)$;

- Quizzes and Concept Maps: Quiz 3 with Map $2(r=.352, p<.05)$, Map $3(r=.413, p<.01)$, and Map $4(r=.408, p<.05)$;

- Concept Maps: Map 1 Research Foundations with Map 2 Basic Statistics and Quantitative Designs $(r=.580, p<.001)$ and Map 3 Qualitative Designs $(r=.468, p<.01)$; Map 2 with Map $3(r=.818, p<.001)$ and Map 4 Mixed Methods and Action Research $(r=.494, p<.01)$; and, Map 3 with Map $4(r=.645, p<.001)$;

- Concept Maps and Final Project: Map $1(r=.498, p<.001)$, Map $2(r=.520, p<.001)$, Map $3(r=.573, p<.001)$, and Map $4(r=.406, p<.05)$.

These results are evidence of positive associations between Develop-, Integrate-, and Perform-level competency scores, and empirical support for the addition of extra credit quizzes. Scores from Quiz 3 directly and Quiz 2 indirectly were linked to the ability to explain relationships between key research paradigms and methodologies (SLO2), differentiate between major components of research reports (SLO3), and develop research evaluation strategies (SLO4). Further, performance on Quiz 3 and on all concept maps assignments were positively associated with the ability to critique research reports independently (SLO5). Quizzes 1 scores did not correlate with another or score and 4 scores showed no significant correlations and Map 4 scores did not correlate with the final project scores. Both require further investigation and possible updates.

\section{Reflection on Results}

The body of evidence from assessment outcomes, student feedback, and design principles support the assertion that the Phase 3 course is an improvement over the Phase 1 version. The design, structure, content, and delivery are in alignment with the course's RMS consumer purpose, which now clearly differentiates this course from the other core courses in the RMS curriculum. The current and similar designs can also be used to address issues of abstract and generic presentation (Barr, 2014), sequencing within a course (Barron \& Apple, 2014), and perhaps begin to tackle students' research and statistics apprehension (Coleman \& Conrad, 2007; Cook, 1998; Davis, 2003; Huang, 2018; Rodriguez \& Toews, 2005; Shenk et al., 2001; Smith \& Martinez-Moyano, 2012). The current competency-based design and assessments are also in alignment with master's degree-level preparation (CoRE Project Team, 2010; ESG, 2025; Lumina, 2014) including preparation for practitioners to be informed RMS consumers in a variety of settings and disciplines (Katzer, Cook, \& Crouch, 1998; Okahana, Augustine, \& Zhou, 2018; McMillan, 2012; Rodriquez \& Toews, 2005; Smith \& MartinezMoyano, 2012). The Phase 3 implementation remains the adopted version though updates regarding the role of Modules 1 and 4 and their respective quizzes continue to be under further review. Also, 
under consideration is integrating digital badges to facilitate micro-credentialing (Casilli \& Hickey, 2016) and prior learning assessment (Singh \& Duvekot, 2013), which in turn, could further support individualized learning experiences and assessment, especially in cases of varying prior knowledge levels. A design for integrating digital badges an example of which is detailed in Author (2018a), could also add to the relevance RMS content and other course content.

\section{Limitations and Conclusion}

Projects of this nature, though valuable in the instructional design process, also have limitations such as those related to survey-based self-reports. Objective data sources such as LMS user logs could also be examined to further validate the role of various instructional components such as the quizzes and peer review. The addition of interviews would have enhanced the understanding of the students' experience throughout the three phases. Also, curriculum design cannot address all barriers including non-instructional ones related to the complex and busy work and personal lives of today's graduate students. Despite these limitations, the emerging evidence from this longitudinal review indicates inquiry-based strategies along with a performance- and competency-based approach can be used to design and teach university-level courses. These methods provide an alternative to the over-use of lower-level learning goals, lecture, and discussion (Fink, 2003), and support master's-level preparation for a variety of settings (CoRE Project Team, 2010; ESG, 2025; Lumina, 2014; Okahana, Augustine, \& Zhou, 2018). Moreover, the use of the RDIP model and other strategies described in this review can be applied to any disciplinary domain and degree level to align traditional classroom experiences with real-world performance expectations (McClelland, 1973) and establish cross-disciplinary meaning to university degrees (CoRE Project Team, 2010; ESG, 2015; Lumina, 2014). Thus, within the larger context of the university teaching and student learning, this longitudinal case study method and the instructional design provide roadmaps for college teachers to engage in a continuous improvement review of their instructional experiences. Instructional development is a personal and professional journey and not a destination, and, this presentation is one example of a journey that is still in progress.

\section{References}

Avsec, S., \& Kocijanic, S. (2016). A path model of effective technology-intensive inquiry-based learning. Educational Technology \& Society, 19(1), 308-320.

Barner, J. C., Desikan, R., Plake, K. S., Purkerson, D. L., Gupchup, G., V., Popovich, N. G., \& Mason, H. L. (1998). Survey of course curricula of graduate programs in social and administrative sciences. American Journal of Pharmaceutical Education, 62(2), 128-135.

Barr, C. J. (2014). Design and evaluation of a post-graduate education in rehabilitation research methods for medical and allied health professionals. Education in medicine Journal 6(2), 8-15. DOI: $10.5959 /$ eimj.v6i2.227

Barron, K. E., \& Apple, K. J. (2014). Debating curricular strategies for teaching statistics and research methods: What does the current evidence suggest? Teaching of Psychology 41(3), 187154.

Bloom, B.S. (Ed.), Engelhart, M.D, Furst, E.J., Hill, W.H, \& Krathwohl D. R (1956). Taxonomy of Educational Objectives, Handbook I: The Cognitive Domain, New York, NY: David McKay Co Inc.

Brennan, C. (2011). The role of research in Art Therapy master's degree programs. Art Therapy: Journal of American Art Therapy Association, 28(3), 140-144.

Journal of the Scholarship of Teaching and Learning, Vol. 19, No. 4, October 2019. josotl.indiana.edu 
Casilli, C., \& Hickey, D. (2016). Transcending conventional credentialing ad assessment paradigms with information-rich digital badges. Information Society, 32(2), 117-129.

https://doi.org/10.1080/01972243.2016.1130500

Coleman, C., \& Conrad C. (2007). Understanding the negative graduate student perception of required statistics and research methods courses: Implications for programs and faculty. Journal of College Teaching \& Learning 4(3), 1-10.

Cook, D. W, (1998). Research education on Rehabilitation Counseling. Rehabilitation Counseling Bulletin, 31, 238-242.

CoRE 2 Project Team. (2010). Tuning educational structures in Europe: A guide to formulating degree programme profiles including programme competences and programme learning outcomes. Retrieved from http://www.core-project.eu/documents/Tuning Guide Publicada CoRe.pdf.

Davis, S. (2003). Statistics anxiety among female African American graduate-level social work students. Journal of Teaching Social Work, 23(3/4), 143-158. DOI: 0.1300/J067v23n03_12

ESG. (2015). Standards and guidelines for quality assurance in the European Higher Education Area. Retrieved February 26, 2019 from https://enqa.eu/wp-content/uploads/2015/11/ESG 2015.pdf

Fink, D. (2003). Creating significant learning experiences: An integrated approach to designing college courses. San Francisco, CA: Jossey-Bass.

Hannafin, M. J., \& Land S. M. (2000). Technology and student-centered learning in higher education: issues and practices. Journal of Computing in Higher Education 12(1), 3-30.

Hannafin, M. J., S. M. Land, Oliver, K. (1999). Open learning environments: foundations, methods, and models. In C. Reigeluth (Ed.), Instructional design theories and models, Vol. 2 (pp. 115-140). Mahwah, NJ: Erlbaum.

Haughton, N. A. (2017). Proposing a competency-based model that connects micro- and macrolevel assessment. In Proceedings of the at $42^{\text {nd }}$ International Conference on Improving University Teaching, 2017, Tel Aviv, Israel.

Haughton, N. A. (2018a). A design for integrating digital badges and competency-based assessment in Graduate Research Methods Education. In Proceedings of the $12^{\text {th }}$ International Technology, Education and Development Conference, 2018, (March 6-8, 2017), pp.7361-7369.

Haughton, N. A. (2018b). The Development and Implementation of a Short-Term International Practicum for Pre-Service Educators. International Research and Review, 8(1), 1-25.

Huang, L. (2018). A mixed method investigation of social science graduate students' statistics anxiety conditions before and after the introductory statistics course. International Journal of Higher Education, 7(3), 156-162. https://doi.org/10.5430/ijhe.v7n3p156

Jonassen, D. H. (1996). Computers in the classroom: Mindtools for critical thinking. Columbus, $\mathrm{OH}$ : Merrill/Prentice-Hall.

Jonassen, D. H. (2000). Toward a design theory of problem solving. Educational Technology Research and Development 48(4), 63-85.

Jonassen, D., \& Grabowski, B. (1993). Handbook of individual differences, learning, and instruction. Hillsdale, NJ: LEA.

Katzer, J., Cook, K. H., \& Crouch, W. W. (1998). Evaluating information: A guide for users of social science research. Boston, MA: McGraw-Hill.

Kim, M. C., \& Hannafin, M. J. (2011). Scaffolding problem solving in technology-enhanced learning environments (TELEs): Bridging research and theory with practice. Computers \& Education 56, 403-417. http://dx.doi.org/10.1016/j.compedu.2010.08.024

Lumina Foundation (2014). The Degree Qualifications Profile: A learning-centered framework for what college students should know and be able to do to earn the associate, bachelor's or master's degree. Retrieved February 26, 2019 from http://degreeprofile.org/press four/wpcontent/uploads/2014/09/DQP-web-download.pdf. 
Mayer, R. E., and Wittrock, M.C. (2006). Problem solving. In P. A. Alexander, \& P. H. Winne (Eds.). Handbook of educational psychology (2nd ed.). (pp. 287-304) New York: Macmillan.

McClelland, D. C. (1973). Testing for competence rather than for "intelligence. American Psychologist, $28,1-14$.

McMillan, James (2012). Educational Research: Fundamentals for the Consumer (6 ${ }^{\text {th }}$ edition). New York, NY: Pearson Education, Inc.

Okahana, H., Augustine, R. M., \& Zhou, E. (2018). Master's admissions: Transparency, guidance, and training. Washington, DC: Council of Graduate Schools. Retrieved March 16, 2019 from https://cgsnet.org/publication-pdf/5396/CGS Masters Web Final.pdf.

Pintrich, P. R., \& De Groot, E. V. (1990). Motivational and self-regulated learning components of classroom academic performance. Journal of Educational Psychology, 82(1), 33-40. http://dx.doi.org/10.1037/0022-0663.82.1.33

Rodriguez, A., \& Toews, M. L. (2005). Training students to be better consumers of research: Evaluating empirical research reports. College Teaching, 53(3), 99-101.

Rothwell, W.J., \& Gaber, J. M. (2011). Competency-based training. Alexandria, VA: American Society for Training and Development.

Saunders-Steward, K., Gyles, P., \& Shore, B. (2012). Student outcomes in inquiry instruction: A literature-derived inventory. Journal of Advanced Academics, 23(1), 5-31. DOI: $10.1177 / 1932202 X 11429860$.

Scardamalia, M., \& Bereiter, C. (2010). A brief history of knowledge building. Canadian Journal of Learning \& Technology, 36(1), 1-16. http://dx.doi.org/10.21432/T2859M

Schunk, D. H. (2012). Learning theories: An educational perspective ( $6^{\text {th }}$ ed.). Boston, MS: Pearson Education, Inc.

Shenk, D., Rowles, G. D., Peacock, J. R., Mitchell, J., Fisher, B. J., \& Moore, K. S. (2001). Teaching research in gerontology: Toward a cumulative model. Educational Gerontology, 27, 537-556. https://doi.org/10.1080/036012701753122884

Singh, M., \& Duvekot, R.C. (Eds.). (2013). Linking recognition practices to qualifications frameworks. International exchange of experiences and strategies. Hamburg: UNESCO Institute for Lifelong Learning.

Smith, A. E., \& Martinez-Moyano, I. J. (2012). Techniques in teaching statistics: Linking research production and research use. Journal of Public Affairs Education, 19(1), 107-136. https://doi.org/10.1080/15236803.2012.12001674

Tashakkori, A., \& Teddlie, C. (2003). Issues and dilemmas in teaching research methods courses in social and behavioral sciences: US perspective. International Journal of Social Research Methodology, 6(1), 61-77. DOl: 10.1080/13645570110106163

United States Department of Education, National Center for Educational Statistics. (2002). Defining and assessing learning: Exploring competency-based initiatives. (NCES 2002-159). Prepared by Elizabeth A. Jones and Richard A. Voorhees, with Karen Paulson, for the Council of the National Postsecondary Education Cooperative Working Group on Competency-Based Initiatives. Washington, DC: 2002 Retrieved from http://nces.ed.gov/pubs2002/2002159.pdf.

Voorhees, R. A. (2001). Competency-based learning models: A necessary future. In R. A. Voorhees (Ed.). New Directions for Institutional Research: No 110. Measuring what matters: Competency-based learning models in higher education (pp. 5-13). San Francisco: Jossey-Bass.

Vygotsky, L. S. (1978). Mind in society: The development of higher psychological processes. (M. Cole, Trans.). Cambridge, MA: Harvard University Press.

Wiggins, G., \& McTighe, J. (2005). Understanding by design. Alexandria, VA: Association for Supervision and Curriculum Development. 
Wong, D. W. (1997). Rehabilitation counseling research. Rebabilitation Education, 11(3), 185-190.

Wongpinunwatana, N., Jantadej, K, \& Jantachoto, J. (2017). Enhancing creative thinking in business research classes: Classroom action research. Journal of Higher Education Theory and Practice, 17(8), 43-57. 